\title{
Optimal Power Flow based Congestion Management Methods for Competitive Electricity Markets
}

\author{
Ashish Saini and A.K. Saxena
}

\begin{abstract}
Congestion management is one of the major tasks performed by system operators to ensure the operation of transmission system within operating limits. In the emerging electric power market, the congestion management becomes extremely important and it can impose a barrier to the electricity trading. In the present paper, a concept of transmission congestion penalty factors is developed and implemented to control power overflows in transmission lines for congestion management. Three methods based on optimal power flow are proposed to alleviate congestion in transmission lines and tested. The first two methods require re-dispatching of generators and changes in capacitors' reactive support only. They can be differentiated on the basis of economic cost involved in making required changes to above variables. The third method deals with load curtailment scheme based on willing to pay charges paid for different transactions in the system to avoid congestion. The formation of different categories for charging willing to pay charges from pool consumers is new feature of this scheme.
\end{abstract}

Index Terms - Adjustment Bids, Congestion Management, Electricity markets and Optimal Power Flow.

\section{INTRODUCTION}

Congestion results when power flows in the transmission line are higher than allowed by the operating reliability limits. In a competitive electricity market, congestion occurs when the transmission network is unable to accommodate all of the desired transactions due to violation of system operating limits. Congestion management means the activities of the transmission system operator to relieve transmission constraints in competitive electricity market. In the present day competitive power market, each utility manages the congestion in the system using its own rules and guidelines utilizing a certain physical or financial mechanism. Various congestion management schemes suitable for different electricity market structure have been reported in literature. Hogan proposed the contract network and nodal pricing approach [1] using the spot pricing theory [2] for pool type market. Chao and Peck [3] proposed an alternative approach which is based on parallel markets for link based

Ashish Saini is with the Electrical Engineering Department, Faculty of Engg., Dayalbagh Educational Institute, Agra-282110, India. (corresponding author e-mail: ashish_711@ rediffmail.com).

A.K. Saxena is with the Electrical Engineering Department, Faculty of Engg., Dayalbagh Educational Institute, Agra-282110, India. (e-mail: aksaxena61@ hotmail.com). transmission capacity rights and energy trading under a set of rules defined and administered by the System Operator (SO). A congestion management approach after the deregulation of the Slovenian power system is presented in [4] and [5]. The method is based on countertrade method where the system operator, based on technical and economic data, decides the optimal redispatch that eliminates congestion. Singh et. al. [6] has proposed dynamic security constrained congestion management in an unbundled electric power system. In [7], the zones have been determined based on lines real and reactive transmission congestion distribution factors in a zonal/cluster-based congestion management approach.

Several Optimal Power Flow (OPF) based congestion management schemes for multiple transactions also have been proposed. An approach using the minimum total modification to the desired transactions for relieving congestion is presented in [8]. A variant of this least modification approach [9] used a weighting scheme with the weights being the surcharges paid by the transactions for transmission usage in the congestion-relieved network. In [10], an OPF based approach that minimizes cost of congestion and service costs is proposed. In [11], a new mechanism of congestion management in multilateral transaction networks has been developed based on physical flows.

There are two broad paradigms that may be employed for congestion management. These are the cost-free means and the not-cost-free means [12]. The former include actions like outaging of congested lines or operation of transformer taps, phase shifters or FACTS devices. These means are termed as cost-free only because the marginal costs (and not the capital costs) involved in their usage are nominal.

The not-cost-free means include:

1) Rescheduling generation

Here, system operator re-dispatches power generation in such a way, that resulting power flows does not overload any line. Every generation unit can bid an increase or decrease of its production in a similar manner as this is done on a balancing market, while the responsibility of system operator is to select bids in efficient way. Somehow, countertrade approach based congestion management can be viewed as simplified optimal power flow problem, where optimization variables are re-dispatch of the active power production and criteria function is minimum of the costs related to this active power re-dispatch. 
2) Prioritization and curtailment of loads/transactions

A parameter termed as
willingness-to-pay-to-avoid-curtailment was introduced in [9]. This can be an effective instrument in setting the transaction curtailment strategies which may then be incorporated in the optimal power flow framework.

In this paper, section II is a brief introduction of GA-Fuzzy optimization method is given. The GA-Fuzzy OPF is tested and found better than various OPF methods based on classical optimization techniques and GA variants by authors and already reported in reference [13]. In section III, the procedure for determining transmission congestion penalty factors is explained. These transmission congestion penalty factors are helpful in deciding appropriate re-dispatchment of dispatchable resources. Section IV covers congestion management methods on GA-Fuzzy based OPF formulations incorporating (1) and hybrid type i.e. both (1) and (2), above are presented and tested on IEEE 30-bus system. The function of proposed congestion management methods based on GA-Fuzzy OPF is to modify system dispatch to ensure secure and efficient system operation based on the existing operating condition. It would use the dispatchable resources (i.e. real and reactive power generations and capacitor reactive supports) and controls (i.e. transformer tapings) subject to their limits and determine the required curtailment of transactions to ensure uncongested operation of the power system. A new load curtailment scheme for pool loads is proposed where all connected loads are divided into three different groups depending on their willingness to pay up to certain load curtailment value.

\section{GA-FUZZY APPROACH FOR OPF SOLUTION}

The GA-Fuzzy optimization technique has been already validated by Saini et al., [13] for OPF on 26-bus power system data, 6-bus power system data and IEEE 30-bus power system data. In this approach the ranges of crossover probability $\left(P_{c}\right)$ and mutation probability $\left(P_{m}\right)$ are divided into LOW, MEDIUM and HIGH membership functions and each function is given some membership values.

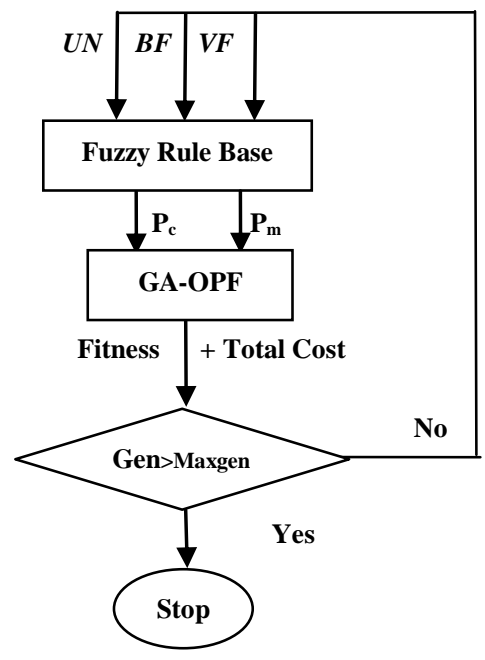

Fig.1 GA-Fuzzy approach for OPF problem solving

Fig. 1 is a diagrammatic representation of an approach to incorporate fuzzy logic to GA based OPF solution. The GA parameters $\left(P_{c}\right.$ and $\left.P_{m}\right)$ are varied based on the fitness function values as per the following logic:

1) The values of the best fitness for each generation $(B F)$ is expected to change over a number of generations, but if it does not change significantly over a number of generations $(U N)$ then this information is considered to cause changes in both $P_{c}$ and $P_{m}$.

2) The diversity of the population is one of the factors, which influences the search for a true optimum. The variance of the fitness values of objective function $(V F)$ of the population is a measure of diversity which is used to change $P_{c}$ and $P_{m}$.

In this approach the ranges of $P_{c}, P_{m}, B F, U N$ and $V F$ are divided into three triangular functions and each is given some membership values.

\section{Transmission CONGESTiOn PENALty FACTORS}

A concept of transmission congestion penalty factors is developed and implemented to control line overflows in proposed GA-Fuzzy approach for congestion management. Transmission congestion penalty factor for each transmission line is computed which can adopt a suitable value depending upon amount of power flow (in MVA) above/below the maximum limit. Therefore, the congested line/lines and lines near to congested line/lines have higher values of transmission congestion penalty factors than other lines in the system. A base case situation is considered for congestion management. This base case refers to optimal settings of real power generation schedule, transformer tap settings and capacitor reactive support settings under normal state and with these settings now system is subjected to congestion (with one/more than one line limits is/are violated).

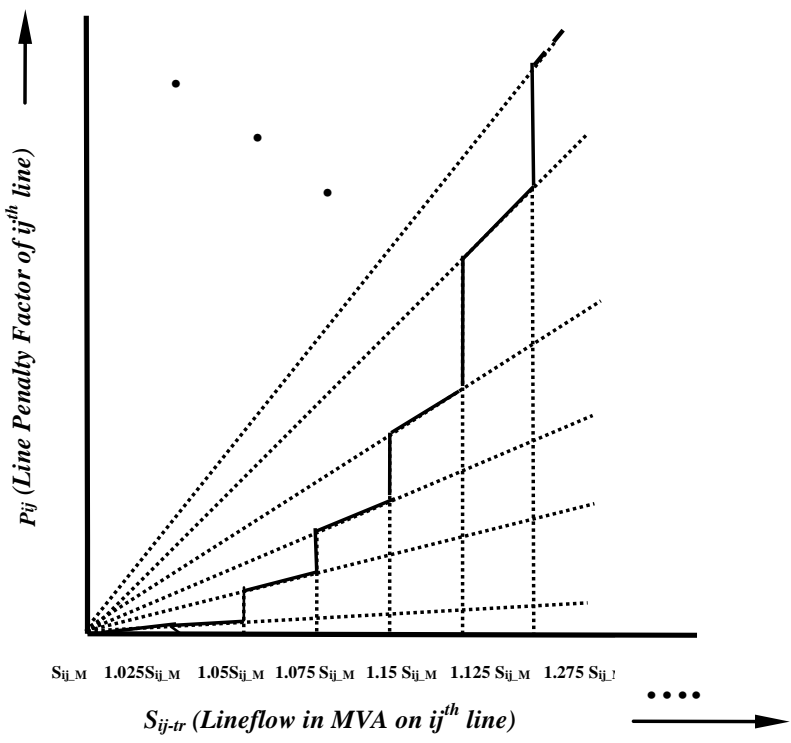

Fig.2 Graphical representation of penalty factors as straight lines

\section{A. Determination of transmission congestion penalty factors}

The following steps are followed to compute these penalty factors. 
Step 1. Load flow solution and line flows $\left(S_{i j \text {-base }}\right)$ are obtained for base case.

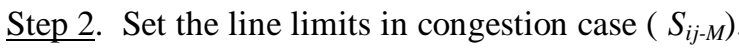

Step 3. GA-Fuzzy approach $[13,15]$ is used to generate population of different generation schedules satisfying equality and non-equality constraints (except line flows limits).

Step 4. Line flows $\left(S_{i j-t r}\right)$ are calculated for each such generation schedule and line penalty factors $\left(P_{i j}\right.$, where $i$ and $j$ denote bus nos. between which transmission line is connected) are calculated according to the logic given below: $P_{i j}=\left\{\begin{array}{lr}0 & \text { when } S_{i j-t r} \leq S_{i j-M} \\ m_{i j} * S_{i j-t r} & , \quad \text { when } S_{i j-t r}>S_{i j-M}\end{array}\right.$ where, $m_{i j}=$ slope decided by $S_{i j-t r}$ and $S_{i j-M}$ as per Table I. $P_{i j} \mathrm{~s}$ are piecewise linear functions which are dependent on overflows on transmission lines (i.e. how much times power flow on any transmission line exceeds its maximum limit). Line penalty factors can be graphically represented as shown in Fig.2.

Step 5. Another parameter, line_flow_sum representing cumulative effect of penalty factors and transmission line flows in congestion is computed as follows:

$$
\text { line } \text { flow }_{-} \text {sum }=\sum_{l=1}^{n_{l}} P_{i j} * S_{i j-t r}
$$

where $n_{l}=$ No. of transmission lines.

These new types of transmission congestion penalty factors have two advantages. First, separate slope for penalty factor of each transmission line is determined depending upon power overflow above rated line flow value of that transmission line. It means that line with lesser power overflow will have lower value of slope, and thus will result small value of penalty factor. Similarly, it is understood that line with comparatively higher power overflow will have higher value of penalty factor. This adaptive feature is helpful in finding right solution (optimal values of control parameters e.g. real power generation, transformer tapping and capacitors values) by search techniques such as GA. Secondly, only single logic mentioned in step-4 works for determining these congestion penalty factors based on magnitude of power overflow in the line/lines. Therefore, no difficulty arises in choosing suitable values of penalty factors.

\section{Proposed Methods For CONGESTION MANAGEMENT}

Three methods are proposed with different objectives using GA-Fuzzy optimal approach and are explained below:

Method-1. Objective of minimization of line overflows only. Method-2. Objective of minimization of line overflows alongwith (real power generation + reactive power generation) redispatch cost and change in capacitor support cost.

Method-3. Objective of minimization of line overflows along with (real power generation + reactive power generation) redispatch cost, change in capacitor support cost and load curtailment.

Mathematical functions representing redispatch cost of real power generation, reactive power generation and change in capacitor support cost are given below. The real power redispatch cost $C_{a d j}\left(\Delta P_{g, k-m}\right)$ is computed by adjusting generation of each generating unit less or more than base case value, with the help of adjustment bids characteristics curves shown in Fig. 3. These curves are decided by special adjustment bids $C_{a d j, P g, k-m}$ invited from all the generator units for generating power less or more than base case values. Therefore, real power redispatch cost can be expressed as:

$C_{a d j}\left(\Delta P_{g, k-m}\right)=C_{a d j, P g, k-m} * \Delta P_{k-m} \quad \$ / h r$

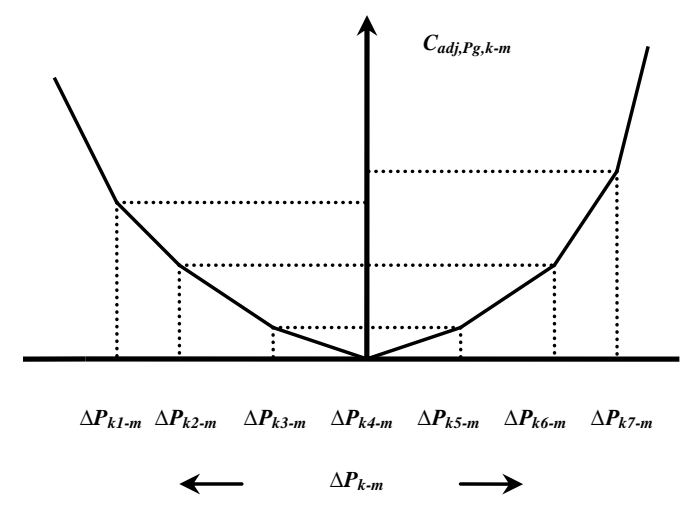

Fig.3 Adjustment bid characteristic representing cost function of the change of active power production at the kth generator

The reactive power cost of generator is also called opportunity cost [14]. The reactive power output of a generator will reduce its active power generation capability which can serve at least as spinning reserve, and the corresponding implicit financial loss to generator is modeled as an opportunity cost. Therefore reactive power redispatch $\operatorname{cost} C_{a d j}\left(\Delta Q_{g, k-m}\right)$ of generator as defined by [7] is:

$C_{a d j}\left(\Delta Q_{g, k-m}\right)=\left|C_{p g}\left(S_{G, \max k-m}\right)-C_{p g}\left(\sqrt{S_{G, \max k-m}^{2}-\Delta Q_{g, k-m}^{2}}\right)\right| k$ profit $\$ / h r$ (2) where, $C_{p g}\left(P_{G, k-m}\right)=a_{k}+b_{k} P_{G, k-m}+c_{k m} P_{G, k-m}^{2}$

i.e the cost of active power generation is modeled by above quadratic function. Where $a_{k}, b_{k}$ and $c_{k}$ are costs coefficients of $k^{\text {th }}$ generator and $S_{G, \max k-m}$ is the nominal maximum apparent power of generation assumed that $P_{G_{\max }, k-m} \approx S_{G_{\max }, k-m}$ and kprofit is the profit rate of active power generation taken between 5-10\% [14].

The equivalent cost for return on the capital investment of the capacitors, which is expressed as their depreciation rates (the life span of capacitors is assumed as 15 years) is computed as

$$
\begin{aligned}
C\left(Q_{C, k c-m}\right) & =Q_{C, k c-m} \frac{(\$ 11600 / M \text { var })}{(15 * 365 * 24 * h) \text { hour }} \\
& =Q_{C, k c-m} * \$ 13.24 /(100 M \text { var hour })
\end{aligned}
$$

where $h$ is the average usage rate of capacitors taken as $2 / 3$. Equation (3) is a linear cost function with the slope of $\frac{d C_{a d j, k c-m}\left(Q_{C, k c-m}\right)}{d Q_{C, k c-m}}=\frac{\$ 13.24}{(100 M \text { var hour })}$, which can be approximately represented as:

$C_{a d j}\left(\Delta Q_{C, k c-m}\right)=\Delta Q_{C, k c-m} *(13.24 / 100) \$ / h r$

Method-1. Objective of minimization of line overflows only 
Step 1. Real power generation redispatch $\Delta P_{g, k-m}$, reactive power generation redispatch $\Delta Q_{g, k-m}$ and change in capacitor reactive support $\Delta Q_{C, k l-m}$ are computed for each valid generation schedule in population, where $k=$ generating unit no., $k c=$ capacitor unit no. and $m=$ no. of generation schedule in population.

Step 2. Correspondingly, redispatch costs of real power generation $C_{a d j}\left(\Delta P_{g, k-m}\right)$, reactive power generation $C_{a d j}\left(\Delta Q_{g, k-m}\right)$ and change in capacitor reactive support $C_{a d j}\left(\Delta Q_{C, k c-m}\right)$ are computed as per equations (1), (2) and (4) respectively.

Step 3. Fitness of each generation schedule in a population is calculated as:

$$
\text { Fitness }=\frac{1}{A * \text { line } \_ \text {flow_sum }}
$$

Step 4. Finally values of real and reactive power generation schedule, transformers tapping values, bus voltages, capacitor reactive support values and line flows calculated in last generation of GA-Fuzzy based optimization approach.

\section{Method-2. Objective of minimization of line overflows} alongwith (real power generation + reactive generation) redispatch cost and change in capacitor support cost

1) Step1 and Step 2 of Method-1 are followed.

2) Fitness of each generation schedule in a population is calculated as:

$$
\text { Fitness }=\frac{e^{-B \times\left(\sum_{g}^{N G} C_{a d j}\left(\Delta P_{g, k-m}\right)+\sum_{g}^{N G} C_{a d j}\left(\Delta Q_{g, k-m}\right)+\sum_{c}^{N C} C_{a d j}\left(\Delta Q_{C, k l-m}\right)\right)}}{A \times \text { line_flow_sum }}
$$

where $A$ and $B$ are numerical constants.

3) Step 4 of Method-1 is followed.

4) Fitness of each generation schedule in a population is calculated as:

Fitness $=$

$$
\frac{e^{\left.-B \times\left(\sum_{g}^{N G} C_{a d j}\left(\Delta P_{g, k-m}\right)+\sum_{g}^{N G} C_{a d j}\left(\Delta Q_{g, k-m}\right)+\sum_{c}^{N C} C_{a d j}\left(\Delta Q_{C, k c-m}\right)+\sum_{i=1}^{3} K_{i}\left(\sum_{k l}^{N L}\left(P_{d, k l-m, g r-i}\right)\right) \sum_{k l}^{N L}\left(P_{d, k l-m, b a x-i}\right)\right)^{2}\right)}}{A \times \text { line_flow_sum }}
$$

where $A, B$ and $K_{i}$ are numerical constants.

5) Step 4 of Method-1 is followed.

\section{RESUlTS AND DisCUSSION}

The proposed methods are implemented on IEEE 30 bus system. The busdata, linedata including generator cost coefficients are taken from $[15,16]$. The bilateral and multilateral transactions details are given in Appendix and [17] also. Line $(8,28)$ get congested (exceeding flow limit of 12 MVA) if outage of line $(6,28)$ is considered.

Figures 4, 5 and 6 show the convergence of different parameters alongwith crossover probability and mutation probability variations. The line flow at line $(8,28)$ violates line limit of 12 MVA under congestion state (16.64 MVA). The results tabulated in Table II-III show that although Method-1 controls better (11.921 MVA) than Method-2 (11.921 MVA, when kprofit $=5 \%)$ but congestion relief charges are less for Method-2 than Method-1. The high congestion relief charges of Method-1 are resulted mainly due to high real power generation redispatch cost because fitness function does not take total (real + reactive) redispatch cost into account. In Method-2 a controlling action to check power overflow is dominant over economic redispatchment cost feature throughout the GA-Fuzzy based optimization procedure.

As per Table IV, Method-2 has slightly lesser load bus voltage variation (i.e. between maximum and minimum load bus voltages) with very small increment in average system voltage value (i.e. average of all bus voltages of the system). It means that from voltage point of view Method-2 is not inferior than Method-1, although this particular aspect requires verification for other power systems also.

In Method-3, a load curtailment feature is also added in fitness function by mathematical modeling. This feature enables pool customers to pay extra charges in order to avoid congestion. This method can be applicable in deregulated environment as it seems to be fair, transparent and consumer satisfaction to great extent. In Fig. 6, convergence of total load curtailment cost and line flow in line $(8,28)$ are shown.

As per Table V, Load Group-3 has maximum and Load Group-1 has minimum load curtailment among all three load groups. This kind of priority is set up by selection parameter $K_{i}$ (refer equation (7)) in fitness function for each load group. The Load Group-1 has highest value and Load Group-3 has lowest value of $K_{i}$. respectively.

\section{CONCLUSION}

The transmission congestion management is one of the critical and important task of the ISO for the smooth functioning of competitive electricity market. The ISO in a competitive electricity market is responsible for determining the necessary actions to ensure that violations of the grid constraints occur. A hybrid strategy based having two stages is also formed on the basis of three methods developed and tested on IEEE 30 bus system. In first stage, Method-1 or Method-2 can be used. If congestion is still not avoidable then under second stage Method-3 with load-curtailment and willingness to pay feature can be used. With reference to the proposed congestion management methods, setting priorities (such as economic re-dispatch cost of generators, effect on operating cost due to changes in transformer tapings and load curtailment schemes) in a GA-Fuzzy optimization framework can be extension of this work.

\section{APPENDIX}

BILATERAL AND MULTILATERAL TRANSACTIONS FOR IEEE 30-BUS SYSTEM.

\begin{tabular}{cccccccc}
\hline \multicolumn{2}{c}{ Bilateral Transactions } & & \multicolumn{4}{c}{ Multilateral Transactions } \\
\cline { 1 - 2 } \cline { 5 - 7 } From bus & To bus & Size $(\mathrm{MW})$ & & From bus & Size (MW) & To bus & Size (MW) \\
\hline 9 & 13 & 5 & & 6 & 4 & 11 & 2 \\
22 & 25 & 5 & & 7 & 2 & 13 & 3 \\
& & & & & & 14 & 1 \\
\hline
\end{tabular}

\section{REFERENCES}

[1] Federal Energy Regulatory Commission (FERC). "Regional Transmission Organizations", Washington, DC, Docket RM99-2-000, Order 2000, 20 Dec., 1999.

[2] Thilo Krause, "Congestion Management in Liberalized Electricity Markets- Theoretical Concepts and International Application", EEH Power Systems Laboratory, Eidgenőssische Technische Hochschule, Zürich, May 2005. 
[3] W.W. Hogan, Contract networks for electric power transmission, J. Regul. Econ. 4 (1992), pp. 211-242.

[4] F.C Schweppe, M.C. Caramanis, R.D. Tabors, R.E. Bohn, “ Spot pricing of Electricity", Kluwer, Norwell, MA, 1988.

[6] David Grgič and Ferdinand Gubina, "Implementation of the Congestion Management Scheme in Unbundled Slovenian Power System, IEEE Porto Power Tech Conference 2001, 10th -13th September, Porto, Portugal.

[7] David Grgič and Ferdinand Gubina, "Congestion Management Approach after Deregulation of the Slovenian Power System", IEEE Transactions on Power Systems, 0-7803-7519-X/02, 2002, pp. 1661-1665.

[8] S.N. Singh and K. David, "Congestion management in dynamic security constrained open power markets", Computers and Electrical Engineering, 29 (2003), pp. 575-588.

[9] Ashwani Kumar, S.C. Srivastava, and S.N. Singh, “A Zonal Congestion Management Approach Using Real and Reactive Power Rescheduling", IEEE Trans. On Power Systems, Vol. 19, No. 1, Feb. 2004, pp. 554-561.

[10] F.D.Galiana, M. Illic, " A mathematical framework for tha analysis and management of power transactions under open access", IEEE Trans. On Power Systems, Vol. 13, No. 2, 1998, pp. 681-687.

[11] R.S.Fang and A.K. David, "Transmission Congestion Management in an electricity market”, IEEE Transactions on Power Systems, Vol. 14, No. 3, August 1999, pp. 877-883.

[12] Jian Fu and John W. Lamont, "A Combined Framework for Service Identification and Congestion Management", IEEE Trans. On Power Systems, Vol. 16, No. 1, Feb. 2001, pp. 56-61.

[13] S. Tao, G. Gross, “ A Congestion management allocation mechanism for multiple transactions networks", IEEE Trans. On Power Systems, Vol. 17, No. 3, Feb. 2002, pp. 826-833.

[14] Hans Glavitsch and Fernando Alvardo, "Management of Multiple Congested Conditions in Unbundled Operation of Power System", IEEE Trans. On Power Systems, Vol. 13, Aug. 98, pp. 1013-1019.

[15] Ashish Saini, D.K. Chaturvedi and A.K. Saxena, "Optimal Power Flow Solution: a GA-Fuzzy System Approach”, International Journal of Emerging Electric Power Systems, Vol. 5, No. 1, Article 1, 2006, Available: http://www.bepress.com/ijeeps/vol15/iss1/1.

[5] H. Chao and S. Peck, "A market mechanism for electric power transmission”, J. Regul. Econ. 10, (1996), pp. 25-29.

[16] Y. Dai, Y.X. Ni, C.M. Shen, F.S. Wen, Z.X. Han, Felix F. Wu, “ A study of reactive power marginal price in electricity market", Electric Power Systems Research, 57 (2001), pp. 41-48.

[17] Ashish Saini, D.K. Chaturvedi and A.K. Saxena, "Transmission Pricing Model under Deregulated Environment", Proceedings of 15th Annual IEEE Symposium on Technological Advances and IT Applications, Central Power Research Institute, Bangalore, 23-24 Nov, 2006.

[18] K.Y. Lee, Y.M. Park and J.L. Ortiz, "A United Approach to Optimal Real and Reactive Power Dispatch", IEEE Trans. On Power Apparatus and Systems, Vol. PAS-104, No. 5, May.85, pp. 1147-1153.

[19] L.L. Lai, J.T. Ma, R. Yokoyama and M. Zhao, "Improved Genetic algorithms for Optimal Power Flow under both normal and contingent operation states", Electrical Power and Energy Systems, Vol. 19, No. 5, 1997 , p.p. $287-292$.

Ashish Saini obtained his Ph.D. in Electrical Engineering from Faculty of Engineering, Dayalbagh Educational Institute, Dayalbagh, Agra, India in 2006. Presently, he is working as Senior Lecturer in Elect. Engg. Dept. at Faculty of Engineering, D.E.I., Dayalbagh, Agra, India. His research interests include applications of artificial intelligence techniques in power system optimization, planning and operation of power systems, power system deregulation, transmission pricing and congestion management. He is a life member of System Society of India, Thiruvananthapurum (India) and senior member IACSIT.

A. K. Saxena received his Ph.D. in Electrical Engineering from Faculty of Engineering, Dayalbagh Educational Institute, Dayalbagh, Agra, India in 1994. $\mathrm{He}$ is presently working as Professor in Electrical Engineering at Faculty of Engineering, D.E.I., Dayalbagh, Agra, India. His research interests include power system operation and control, security analysis, energy auditing and demand side management. He is a life member of System Society of India,

Thiruvananthapurum (India) and member of IEEE.

TABLE I. Slope determination for lines representing penalty factors

\begin{tabular}{|c|c|c|c|}
\hline S.No. & $\mathrm{S}_{\mathrm{ij}-\mathrm{tr}}$ & Angle in degrees $(\theta)$ & Slope of line $(\tan \theta)$ \\
\hline 1. & $\leq \mathrm{S}_{\mathrm{ij}-\mathrm{M}}$ & 0 & 0 \\
\hline 2. & $>\mathrm{S}_{\mathrm{ij}-\mathrm{M}} \& \leq 1.025 \mathrm{~S}_{\mathrm{ij}-\mathrm{M}}$ & 2.25 & 0.039 \\
\hline 3. & $>1.025 \mathrm{~S}_{\mathrm{ij}-\mathrm{M}} \& \leq 1.05 \mathrm{~S}_{\mathrm{ij}-\mathrm{M}}$ & 4.5 & 0.079 \\
\hline 4. & $>1.05 \mathrm{~S}_{\mathrm{ij}-\mathrm{M}} \& \leq 1.075 \mathrm{~S}_{\mathrm{ij}-\mathrm{M}}$ & 6.75 & 0.118 \\
\hline 5. & $>1.075 \mathrm{~S}_{\mathrm{ij}-\mathrm{M}} \quad \& \leq 1.1 \mathrm{~S}_{\mathrm{ij}-\mathrm{M}}$ & 9.00 & 0.158 \\
\hline 6. & $>1.1 \mathrm{~S}_{\mathrm{ij}-\mathrm{M}} \& \leq 1.125 \mathrm{~S}_{\mathrm{ij}-\mathrm{M}}$ & 11.25 & 0.199 \\
\hline 7. & $>1.125 \mathrm{~S}_{\mathrm{ij}-\mathrm{M}} \& \leq 1.15 \mathrm{~S}_{\mathrm{ij}-\mathrm{M}}$ & 13.5 & 0.240 \\
\hline 8. & $>1.15 \mathrm{~S}_{\mathrm{ij}-\mathrm{M}} \quad \& \leq 1.175 \mathrm{~S}_{\mathrm{ij}-\mathrm{M}}$ & 15.75 & 0.282 \\
\hline 9. & $>1.175 \mathrm{~S}_{\mathrm{ij}-\mathrm{M}} \& \leq 1.2 \mathrm{~S}_{\mathrm{ij}-\mathrm{M}}$ & 18.00 & 0.325 \\
\hline 10. & $>1.2 \mathrm{~S}_{\mathrm{ij}-\mathrm{M}} \& \leq 1.225 \mathrm{~S}_{\mathrm{ij}-\mathrm{M}}$ & 20.25 & 0.369 \\
\hline 11. & $>1.225 \mathrm{~S}_{\mathrm{ij}-\mathrm{M}} \& \leq 1.25 \mathrm{~S}_{\mathrm{ij}-\mathrm{M}}$ & 22.50 & 0.414 \\
\hline 12. & $>1.25 \mathrm{~S}_{\mathrm{ij}-\mathrm{M}} \& \leq 1.275 \mathrm{~S}_{\mathrm{ij}-\mathrm{M}}$ & 24.75 & 0.461 \\
\hline 13. & $>1.275 \mathrm{~S}_{\mathrm{ij}-\mathrm{M}} \quad \& \leq 1.3 \mathrm{~S}_{\mathrm{ij}-\mathrm{M}}$ & 27.00 & 0.510 \\
\hline 14. & $>1.30 \mathrm{~S}_{\mathrm{ij}-\mathrm{M}} \quad \& \leq 1.325 \mathrm{~S}_{\mathrm{ij}-\mathrm{M}}$ & 29.25 & 0.560 \\
\hline 15. & $>1.325 \mathrm{~S}_{\mathrm{ij}-\mathrm{M}} \& \leq 1.35 \mathrm{~S}_{\mathrm{ij}-\mathrm{M}}$ & 31.50 & 0.613 \\
\hline 16. & $>1.35 \mathrm{~S}_{\mathrm{ij}-\mathrm{M}} \quad \& \leq 1.375 \mathrm{~S}_{\mathrm{ij}-\mathrm{M}}$ & 33.75 & 0.660 \\
\hline 17. & $>1.375 \mathrm{~S}_{\mathrm{ij}-\mathrm{M}} \quad \& \leq 1.4 \mathrm{~S}_{\mathrm{ij}-\mathrm{M}}$ & 36.00 & 0.727 \\
\hline 18. & $>1.4 \mathrm{~S}_{\mathrm{ij}-\mathrm{M}} \& \leq 1.425 \mathrm{~S}_{\mathrm{ij}-\mathrm{M}}$ & 38.25 & 0.788 \\
\hline 19. & $>1.425 \mathrm{~S}_{\mathrm{ij}-\mathrm{M}} \& \leq 1.45 \mathrm{~S}_{\mathrm{ij}-\mathrm{M}}$ & 40.50 & 0.854 \\
\hline 20. & $>1.45 \mathrm{~S}_{\mathrm{ij}-\mathrm{M}} \quad \& \leq 1.475 \mathrm{~S}_{\mathrm{ij}-\mathrm{M}}$ & 42.75 & 0.916 \\
\hline 21. & $>1.475 \mathrm{~S}_{\mathrm{ij}-\mathrm{M}} \quad \& \leq 1.5 \mathrm{~S}_{\mathrm{ij}-\mathrm{M}}$ & 45 & 1.000 \\
\hline 22. & $>1.5 \mathrm{~S}_{\mathrm{ij}-\mathrm{M}} \& \leq 1.525 \mathrm{~S}_{\mathrm{ij}-\mathrm{M}}$ & 47.25 & 1.082 \\
\hline 23. & $>1.525 \mathrm{~S}_{\mathrm{ij}-\mathrm{M}} \& \leq 1.55 \mathrm{~S}_{\mathrm{ij}-\mathrm{M}}$ & 49.5 & 1.171 \\
\hline 24. & $>1.55 \mathrm{~S}_{\mathrm{ij}-\mathrm{M}} \quad \& \leq 1.575 \mathrm{~S}_{\mathrm{ij}-\mathrm{M}}$ & 51.75 & 1.269 \\
\hline 25 . & $>1.575 \mathrm{~S}_{\mathrm{ij}-\mathrm{M}} \quad \& \leq 1.6 \mathrm{~S}_{\mathrm{ij}-\mathrm{M}}$ & 54.00 & 1.376 \\
\hline 26. & $>1.6 \mathrm{~S}_{\mathrm{ij}-\mathrm{M}} \quad \& \leq 1.62 \mathrm{~S}_{\mathrm{ij}-\mathrm{M}}$ & 56.25 & 1.497 \\
\hline 27. & $>1.625 \mathrm{~S}_{\mathrm{ij}-\mathrm{M}} \& \leq 1.65 \mathrm{~S}_{\mathrm{ij}-\mathrm{M}}$ & 58.50 & 1.632 \\
\hline 28. & $>1.65 \mathrm{~S}_{\mathrm{ij}-\mathrm{M}} \quad \& \leq 1.675 \mathrm{~S}_{\mathrm{ij}-\mathrm{M}}$ & 60.75 & 1.786 \\
\hline 29. & $>1.675 \mathrm{~S}_{\mathrm{ij}-\mathrm{M}} \quad \& \leq 1.7 \mathrm{~S}_{\mathrm{ij}-\mathrm{M}}$ & 63.00 & 1.963 \\
\hline 30. & $>1.7 \mathrm{~S}_{\mathrm{ij}-\mathrm{M}} \& \leq 1.725 \mathrm{~S}_{\mathrm{ij}-\mathrm{M}}$ & 65.25 & 2.169 \\
\hline 31. & $>1.725 \mathrm{~S}_{\mathrm{ij}-\mathrm{M}} \& \leq 1.75 \mathrm{~S}_{\mathrm{ij}-\mathrm{M}}$ & 67.50 & 2.414 \\
\hline 32. & $>1.75 \mathrm{~S}_{\mathrm{ij}-\mathrm{M}} \quad \& \leq 1.775 \mathrm{~S}_{\mathrm{ij}-\mathrm{M}}$ & 69.75 & 2.711 \\
\hline 33. & $>1.775 \mathrm{~S}_{\mathrm{ij}-\mathrm{M}} \quad \& \leq 1.8 \mathrm{~S}_{\mathrm{ij}-\mathrm{M}}$ & 72.00 & 3.078 \\
\hline 34. & $>1.80 \mathrm{~S}_{\mathrm{ij}-\mathrm{M}} \quad \& \leq 1.825 \mathrm{~S}_{\mathrm{ij}-\mathrm{M}}$ & 74.25 & 3.546 \\
\hline 35. & $>1.825 \mathrm{~S}_{\mathrm{ij}-\mathrm{M}} \& \leq 1.85 \mathrm{~S}_{\mathrm{ij}-\mathrm{M}}$ & 76.50 & 4.165 \\
\hline 37. & $>1.85 \mathrm{~S}_{\mathrm{ij}-\mathrm{M}} \& \leq 1.875 \mathrm{~S}_{\mathrm{ij}-\mathrm{M}}$ & 78.75 & 5.027 \\
\hline 38. & $>1.875 \mathrm{~S}_{\mathrm{ij}-\mathrm{M}} \quad \& \leq 1.9 \mathrm{~S}_{\mathrm{ij}-\mathrm{M}}$ & 81.00 & 6.314 \\
\hline 39. & $>1.9 \mathrm{~S}_{\mathrm{ij}-\mathrm{M}} \& \leq 1.925 \mathrm{~S}_{\mathrm{ij}-\mathrm{M}}$ & 83.25 & 8.449 \\
\hline 40. & $>1.925 \mathrm{~S}_{\mathrm{ij}-\mathrm{M}} \& \leq 1.95 \mathrm{~S}_{\mathrm{ij}-\mathrm{M}}$ & 85.50 & 12.706 \\
\hline 41. & $>1.95 \mathrm{~S}_{\mathrm{ij}-\mathrm{M}} \& \leq 1.975 \mathrm{~S}_{\mathrm{ij}-\mathrm{M}}$ & 87.75 & 25.452 \\
\hline
\end{tabular}



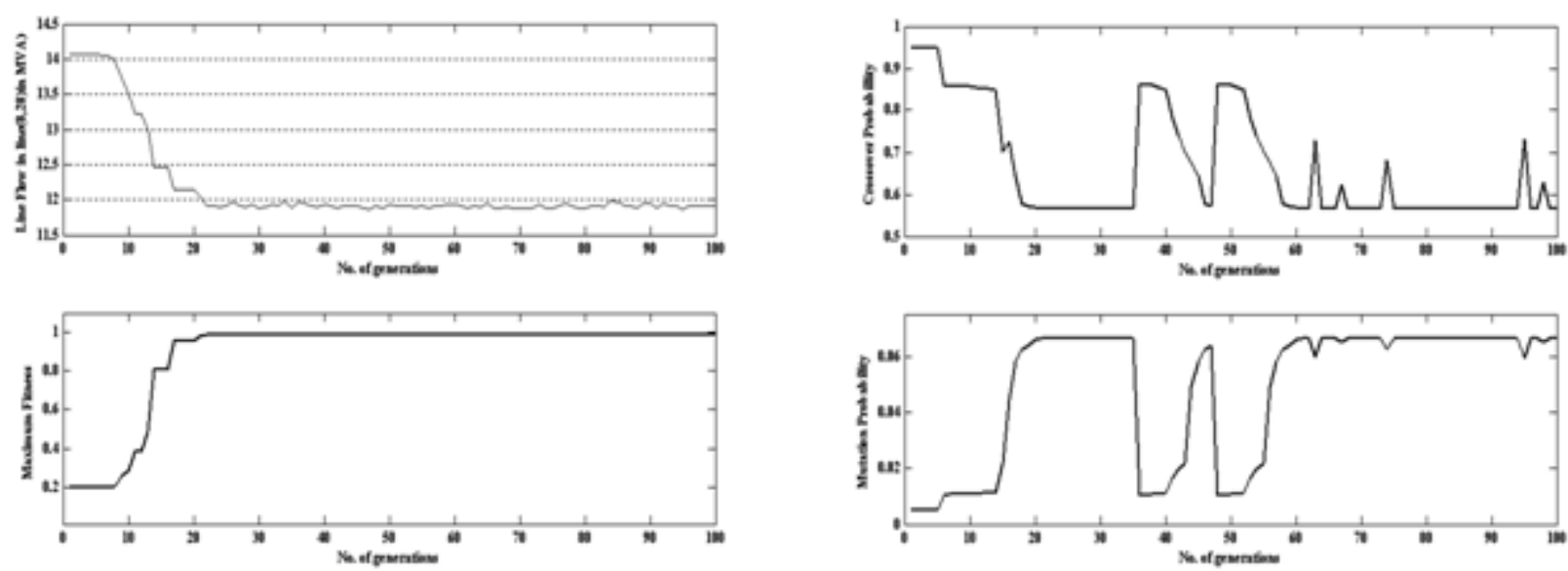

Fig.4 Convergence of different parameters, crossover probability and mutation probability variations using GA-Fuzzy approach for Method-1
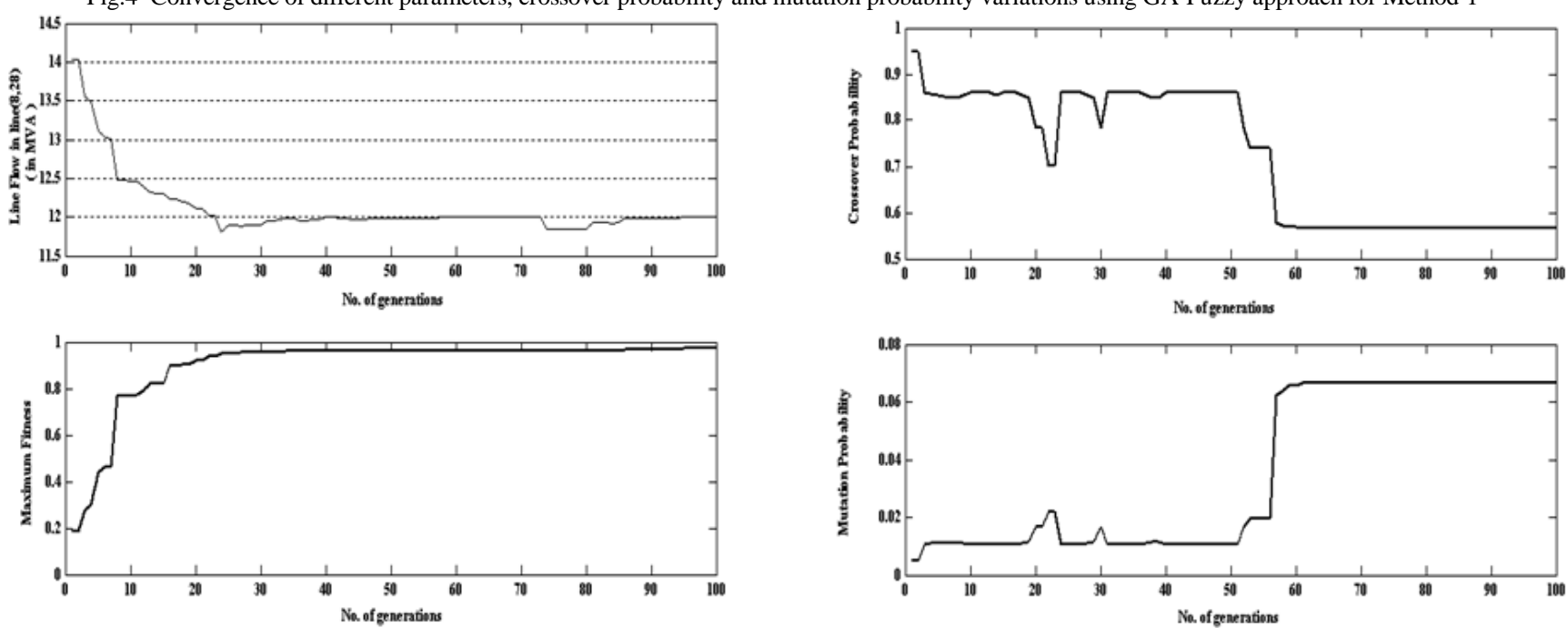

Fig.5 Convergence of different parameters, crossover probability and mutation probability variations using GA-Fuzzy approach for Method-2
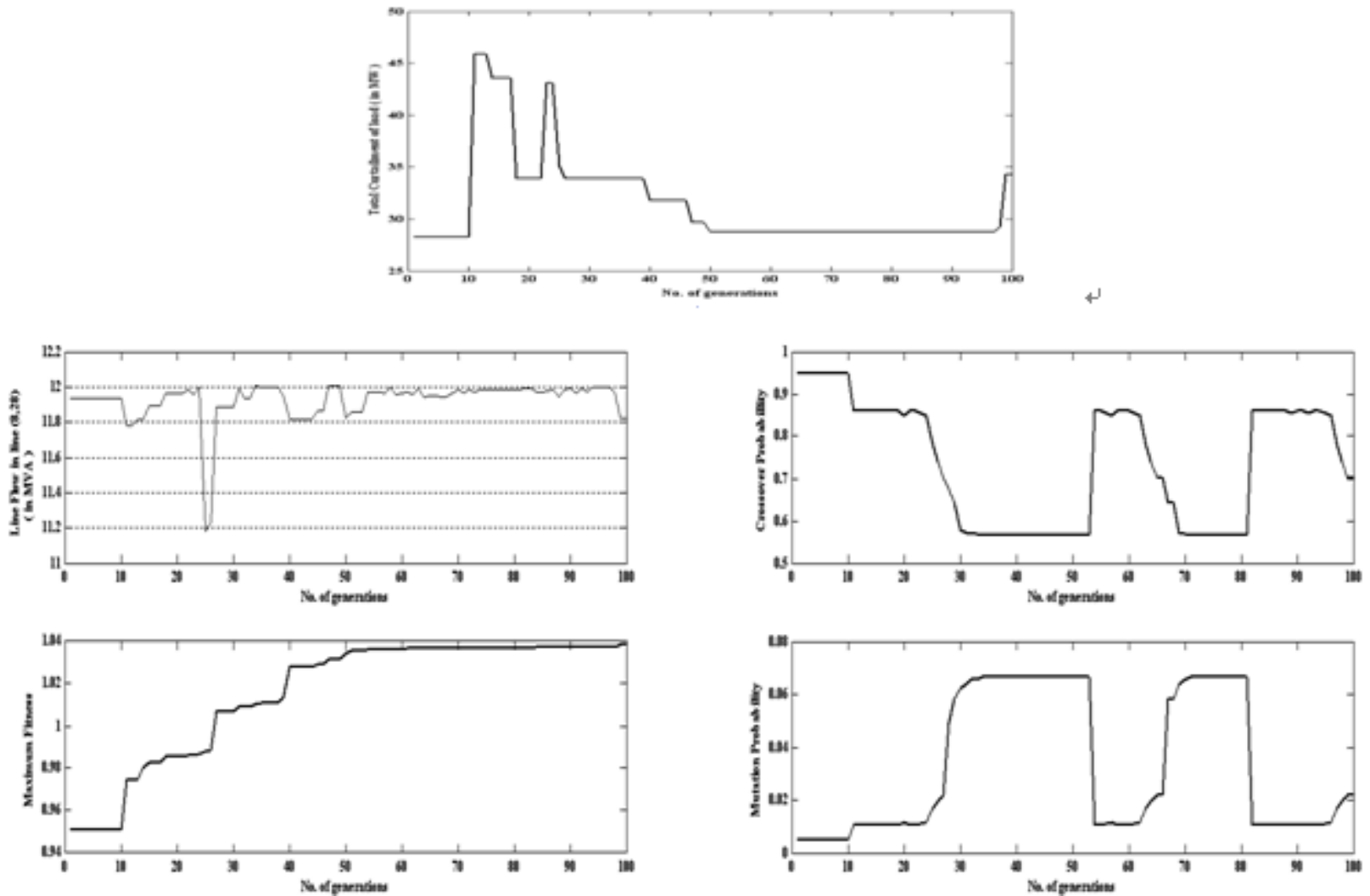

Fig.6 Convergence of different parameters, crossover probability and mutation probability variations using GA-Fuzzy approach for Method-3 
International Journal of Computer and Electrical Engineering, Vol. 2, No. 1, February, 2010 1793-8163

TABLE II. Comparison of re-dispatchment of (Real Power + Reactive Power Generation), change in Capacitor Reactive power Support and Line flow at line $(8,28)$ for Method-1 and Method-2

\begin{tabular}{|c|c|c|c|c|c|c|c|}
\hline \multirow[t]{3}{*}{ S.No. } & \multirow[t]{3}{*}{ Generation at } & \multirow{2}{*}{\multicolumn{2}{|c|}{ In Congestion state }} & \multicolumn{4}{|c|}{ Congestion Management Method } \\
\hline & & & & \multicolumn{2}{|c|}{ Method-1 } & \multicolumn{2}{|c|}{ Method-2 } \\
\hline & & $P_{g}($ in $\mathrm{MW})$ & $Q_{g}$ (in MVAr) & $P_{g}($ in $\mathrm{MW})$ & $Q_{g}($ in MVAr) & $P_{g}($ in $\mathrm{MW})$ & $Q_{g}$ (in MVAr) \\
\hline 1. & Bus 1 & 175.165 & 4.624 & 156.568 & 72.914 & 163.962 & 32.23 \\
\hline 2. & Bus 2 & 48.941 & 29.345 & 33.647 & -4.262 & 41.882 & 39.692 \\
\hline 3. & Bus 5 & 21.176 & 28.21 & 33.941 & 25.8 & 20.765 & 33.403 \\
\hline 4. & Bus 8 & 22.647 & 40.559 & 12.549 & 29.386 & 11.667 & 27.073 \\
\hline 5. & Bus 11 & 12.588 & 17.124 & 26.706 & 8.078 & 26.471 & 22.08 \\
\hline 6. & Bus 13 & 12.00 & 10.263 & 28.8 & 6.634 & 28.031 & -8.37 \\
\hline \multicolumn{2}{|c|}{ Total } & 292.517 & 130.125 & 292.211 & 138.551 & 292.778 & 146.107 \\
\hline \multirow[t]{3}{*}{ S.No. } & \multirow[t]{3}{*}{ Capacitor at } & \multirow{2}{*}{\multicolumn{2}{|c|}{ In Congestion state }} & \multicolumn{4}{|c|}{ Congestion Management Method } \\
\hline & & & & \multicolumn{2}{|c|}{ Method-1 N } & \multicolumn{2}{|c|}{ Method-2, when kprofit $=5 \%$} \\
\hline & & \multicolumn{2}{|c|}{$Q_{C}$ (in MVAr) } & \multicolumn{2}{|c|}{$Q_{C}($ in MVAr) } & \multicolumn{2}{|c|}{$Q_{C}($ in $\mathrm{MVAr}$} \\
\hline 1. & Bus 10 & \multicolumn{2}{|c|}{3.982} & \multicolumn{2}{|c|}{1.585} & \multicolumn{2}{|c|}{2.299} \\
\hline 2. & Bus 12 & \multicolumn{2}{|c|}{0.02} & \multicolumn{2}{|c|}{2.916} & \multicolumn{2}{|c|}{1.037} \\
\hline 3. & Bus 15 & \multicolumn{2}{|c|}{4.149} & \multicolumn{2}{|c|}{0.998} & \multicolumn{2}{|c|}{4.354} \\
\hline 4. & Bus 17 & \multicolumn{2}{|c|}{4.99} & \multicolumn{2}{|c|}{3.043} & \multicolumn{2}{|c|}{1.937} \\
\hline 5. & Bus 20 & \multicolumn{2}{|c|}{4.432} & \multicolumn{2}{|c|}{1.526} & \multicolumn{2}{|c|}{2.114} \\
\hline 6. & Bus 21 & \multicolumn{2}{|c|}{4.354} & 0.80 & & 0.77 & \\
\hline 7. & Bus 23 & \multicolumn{2}{|c|}{4.54} & 3.50 & & 1.15 & \\
\hline 8. & Bus 24 & & & 4.23 & & $1.7 \mathrm{C}$ & \\
\hline 9. & Bus 29 & & & 4.35 & & 3.38 & \\
\hline & tal & & & 22.9 & & 18.8 & \\
\hline Line flow & $(8,28)$ (in $M V A)$ & & & 11.9 & & 11.9 & \\
\hline
\end{tabular}

TABLE III. Comparison of congestion relief charges for Method-1 and Method-2

\begin{tabular}{|c|c|c|c|c|c|}
\hline \multirow[t]{3}{*}{ S.No. } & & \multicolumn{4}{|c|}{ Congestion Management Method } \\
\hline & & \multicolumn{2}{|c|}{ Method-1 } & \multicolumn{2}{|c|}{ Method-2 } \\
\hline & & $C\left(\Delta P_{g}\right)$ (in $\left.\$ / \mathrm{hr}\right)$ & $C\left(\Delta Q_{g}\right)$ (in $\left.\$ / \mathrm{hr}\right)$ & $C\left(\Delta P_{g}\right)($ in $\$ / \mathrm{hr})$ & $C\left(\Delta Q_{g}\right)$ (in $\left.\$ / \mathrm{hr}\right)$ \\
\hline 1. & & -59.823 & 2.0764 & -36.0217 & 0.3343 \\
\hline 2. & & -48.4633 & 1.6359 & -23.3393 & 0.1525 \\
\hline 3. & & 58.2958 & 0.0211 & -1.3936 & 0.0978 \\
\hline 4. & Bus 8 & -35.7547 & 0.3496 & -38.7967 & 0.515 \\
\hline 5. & Bus 11 & 55.1735 & 0.3117 & 54.1465 & 0.0925 \\
\hline 6. & Bus 13 & 67.8 & 0.0412 & 64.5317 & 1.1247 \\
\hline \multicolumn{2}{|c|}{ Total (in $\$ / \mathrm{hr}$ ) } & 37.2283 & 4.4359 & 19.1269 & 2.3169 \\
\hline \multirow[t]{2}{*}{ S.No. } & \multirow[t]{2}{*}{ Capacitor at } & \multicolumn{2}{|c|}{ Method-1 } & \multicolumn{2}{|c|}{ Method-2 } \\
\hline & & \multicolumn{2}{|c|}{$C\left(\Delta Q_{c}\right)$ (in $\left.\$ / \mathrm{hr}\right)$} & \multicolumn{2}{|c|}{$C\left(\Delta Q_{c}\right)$ (in $\left.\$ / \mathrm{hr}\right)$} \\
\hline 1. & Generation at & \multicolumn{2}{|c|}{-0.3174} & \multicolumn{2}{|c|}{-0.2228} \\
\hline 2. & & \multicolumn{2}{|c|}{0.3834} & \multicolumn{2}{|c|}{0.1347} \\
\hline 3. & & \multicolumn{2}{|c|}{-0.4172} & \multicolumn{2}{|c|}{0.0271} \\
\hline 4. & Bus 1 & \multicolumn{2}{|c|}{-0.2578} & \multicolumn{2}{|c|}{-0.4042} \\
\hline 5. & Bus 2 & \multicolumn{2}{|c|}{-0.3848} & \multicolumn{2}{|c|}{-0.3069} \\
\hline 6. & Bus 5 & \multicolumn{2}{|c|}{-0.4703} & \multicolumn{2}{|c|}{-0.4741} \\
\hline 7. & Bus 23 & \multicolumn{2}{|c|}{-0.1373} & \multicolumn{2}{|c|}{-0.4482} \\
\hline 8. & Bus 24 & \multicolumn{2}{|c|}{-0.0596} & \multicolumn{2}{|c|}{-0.3834} \\
\hline 9. & Bus 29 & \multicolumn{2}{|c|}{0.299} & \multicolumn{2}{|c|}{0.1708} \\
\hline \multicolumn{2}{|c|}{ Total (in \$/hr) } & \multicolumn{2}{|c|}{-1.3619} & \multicolumn{2}{|c|}{-1.9071} \\
\hline \multicolumn{2}{|c|}{ Grand Total (in \$/hr) } & \multicolumn{2}{|c|}{40.3023} & \multicolumn{2}{|c|}{19.5367} \\
\hline
\end{tabular}

TABLE IV. Comparison of maximum and minimum voltage levels at Load buses for all the three methods

\begin{tabular}{ccccc}
\hline & & Method-1 & Method-2 & Method-3 \\
\hline \multirow{3}{*}{ Load Bus } & Maximum & Bus 12: 1.048 p.u. & Bus 9: 1.049 p.u. & Bus 9: 1.047 p.u. \\
& Minimum & Bus 30: 0.95 p.u. & Bus 30: 0.956 p.u. & Bus 30: 0.959 p.u. \\
\cline { 2 - 5 } & Difference & 0.098 p.u. & 0.093 p.u. & 0.088 p.u. \\
\hline Average value of system voltage & 1.005533 p.u. & 1.0139 p.u. & 1.0135 p.u. \\
\hline
\end{tabular}

TABLE V. Re-dispatchment of (Real Power + Reactive Power Generation), Change in Capacitor Reactive power Support, Load curtailment and Line flow

\begin{tabular}{ccc}
\hline & at line $(8,28)$ for Method-3 & Method-3 \\
\hline Generation at & $P_{g}$ (in MW) & $Q_{g}$ (in MVAr) \\
\hline & 150.747 & 13.316 \\
Bus 1 & 42.353 & 32.196 \\
Bus 2 & 19.529 & 30.004 \\
Bus 5 & 10.098 & 1.131 \\
Bus 8 & 15.02 & 13.246 \\
Bus 11 & 19.027 & 23.381 \\
Bus 13 & 256.774 & \\
\hline Total & & $Q_{C}$ (in MVAr) \\
\hline Capacitor at & 2.329 \\
Bus 10 & 2.808 \\
Bus 12 & & 1.693 \\
Bus 15 & & 0.401 \\
Bus 17 & & 1.986
\end{tabular}


International Journal of Computer and Electrical Engineering, Vol. 2, No. 1, February, 2010

1793-8163

\begin{tabular}{|c|c|c|c|c|c|c|c|c|}
\hline & $\begin{array}{l}\text { Bus } \\
\text { Bus } \\
\text { Bus } \\
\text { Bus }\end{array}$ & & & & & $\begin{array}{c}1.027 \\
1.115 \\
1.115 \\
3.16 \\
\end{array}$ & & \\
\hline \multicolumn{4}{|c|}{ Total } & & & 15.636 & & \\
\hline \multicolumn{9}{|c|}{ Load $P_{l}$ (in MW) } \\
\hline Load Group-1 & In Congestion & Method-3 & Load Group-2 & In Congestion & Method-3 & Load Group-3 & In Congestion & Method-3 \\
\hline Bus 7 & 22.8 & 21.6232 & Bus 4 & 7.6 & 7.0116 & Bus 2 & 21.7 & 14.56 \\
\hline Bus 8 & 30.0 & 28.4516 & Bus 5 & 94.2 & 86.9071 & Bus 3 & 2.4 & 1.6103 \\
\hline Bus 17 & 9.0 & 8.5355 & Bus 15 & 8.2 & 7.5652 & Bus 10 & 5.8 & 3.8916 \\
\hline Bus 18 & 3.2 & 3.0348 & Bus 16 & 3.5 & 3.229 & Bus 12 & 11.2 & 7.5148 \\
\hline Bus 26 & 3.5 & 3.3194 & Bus 21 & 17.5 & 16.1452 & Bus 14 & 6.2 & 4.16 \\
\hline Bus 29 & 2.4 & 2.2761 & Bus 23 & 3.2 & 2.9523 & Bus 19 & 9.5 & 6.3742 \\
\hline Bus 30 & 10.6 & 10.0529 & Bus 24 & 8.7 & 8.0265 & Bus 20 & 2.2 & 1.4761 \\
\hline Total & 81.5 & 77.2935 & Total & 142.9 & 131.8369 & Total & 59.0 & 39.587 \\
\hline \multicolumn{4}{|c|}{ Line flow at line $(8,28)$ (in MVA) } & & & 11.823 & & \\
\hline
\end{tabular}

Group 1-Load group 1, Group G2-Load group 2, Group 3-Load group 3 